\title{
SUPPORT VECTOR MACHINE PADA INFORMATION RETRIEVAL
}

\author{
Oleh \\ I Ketut Purnamawan \\ Jurusan Manajemen Informatika Fakultas Teknik dan Kejuruan \\ Universitas Pendidikan Ganesha \\ tutpurna@yahoo.com
}

\begin{abstract}
ABSTRAK
SVM merupakan classsifier yang mempunyai keunggulan dapat mengolah data berdimensi tinggi, tanpa mengalami penurunan performa yang signifikan. SVM sekarang ini semakin banyak dipergunakan. Pada information retrieval, SVM juga sudah banyak digunakan, khususnya pada bagian proses klasifikasi. Kemampuan SVM untuk mengolah data berdimensi besar sangat cocok untuk diterapkan pada data teks yang cenderung berdimensi besar. Pada tulisan ini dibahas perbandingan performa SVM dengan performa classsifier lain pada information retrieval. Pembahasan dilakukan berdasarkan hasil penelitian beberapa peneliti. Pada satu penelitian didapatkan bahwa SVM mengungguli classsifier lain. Pada penelitian lain didapatkan performa SVM berimbang dengan classsifier lain. Pada akhir tulisan dibahas mengenai langkah-langkah klasifikasi teks menggunakan SVM. Proses klasifikasi teks ini digunakan pada information retrieval data teks.

Kata kunci : SVM, Information retrieval, classsifier.
\end{abstract}

\begin{abstract}
SVM is classsifier that can process high-dimension data, without a significant loss in performance. SVM is now more widely used. In information retrieval, SVM has also been widely used, especially in the classification process. SVM ability to process high-dimension data is very suitable to be applied to the text data, which is has highdimension data. In this paper discussed the SVM performance comparisons with other classsifier performance in information retrieval. The discussion is based on the results of studies of several researchers. In one study it was found that SVM outperformed other classsifier. In the other study found SVM performance comparable with other classsifier. At the end of the paper, also discussed about the steps of text classification using SVM. This text classification process used in information retrieval of text data.
\end{abstract}

Keywords : SVM, Information retrieval, classsifier.

\section{PEDAHULUAN}

SVM (Support Vector Machine) adalah salah satu classsifier yang sekarang banyak digunakan untuk melakukan berbagai keperluan klasifikasi. Selain untuk klasifikasi, SVM juga digunakan untuk regresi. SVM merupakan binary classifier yang membagi data menjadi dua class dengan sebuah hyperplane. Hyperplane ini tepat berada di tengah-tengah kedua class dengan jarak $d$ ke titik data terdekat untuk masing-masing class. $d$ disebut margin, dan titik-titik data yang berada tepat pada jarak $d$ dari hyperplane disebut support vector. Hyperplane SVM dinyatakan dengan persamaan sebagai berikut.

$$
w \cdot x+b=0
$$


dimana $w$ merupakan normal dari hyperplane, dan $\frac{b}{\|w\|}$ adalah jarak hyperplane ke titik origin. Gambar 1 memperlihatkan hyperplane yang membagi dua buah class.

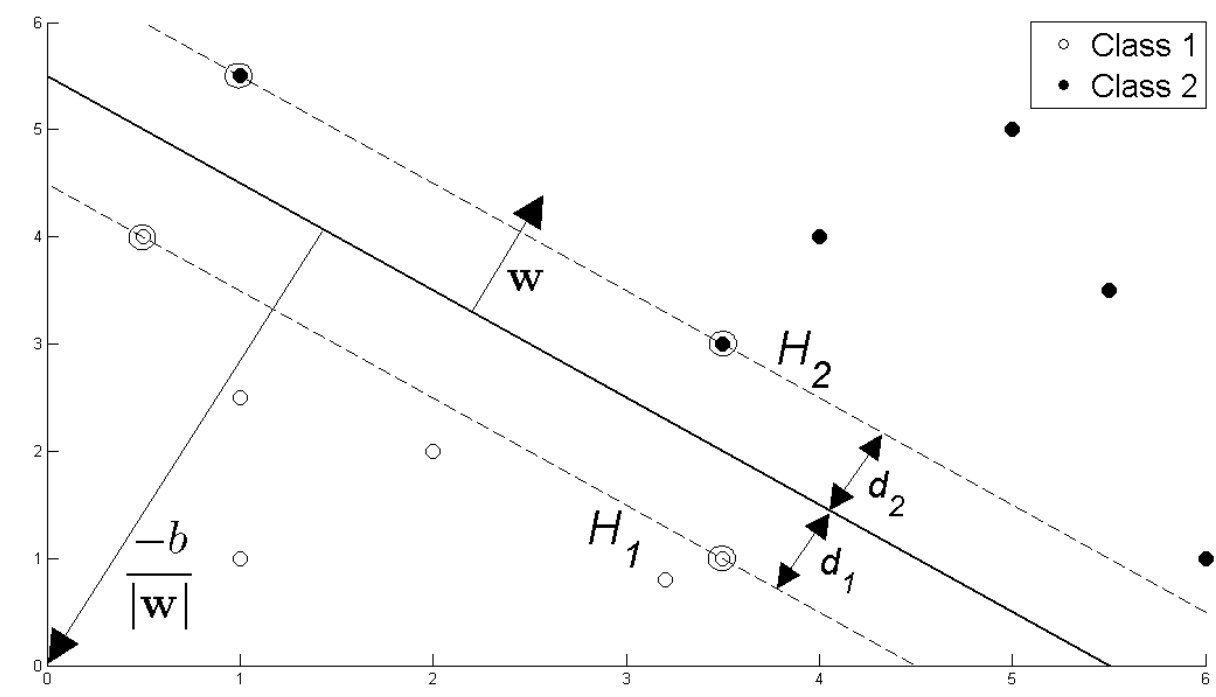

Gambar 1: Hyperplane membagi dua buah class. (sumber gambar: Fletcher (2009))

Titik-titik data yang masuk ke class 1 adalah titik-titik data yang memenuhi persamaan

$$
w \cdot x+b \leq-1
$$

dan titik-titik data yang masuk ke class 2 adalah titik-titik data yang memenuhi persamaan

$$
w \cdot x+b \geq 1
$$

Pada information retrieval SVM juga banyak digunakan, terutama pada proses klasifikasi data. Kemampuannya untuk mengolah data berdimensi besar menjadi keunggulan SVM dibanding dengan classsifier lain. Pada information retrieval data teks, keunggulan SVM untuk mengolah data berdimensi besar dapat dimanfaatkan, karena sifat data teks yang biasanya berdimensi besar. Pada tulisan ini akan dibahas perbandingan performa SVM dengan performa classsifier lain pada information retrieval. Perbandingan dibahas berdasarkan hasil penelitian beberapa peneliti. Di akhir tulisan juga dibahas langkah-langkah klasifikasi data teks. Proses klasifikasi ini digunakan pada proses information retrieval data teks. 


\section{PEMBAHASAN}

\subsection{SVM pada Information Retrieval dan Perbandingannya dengan algoritma- algoritma lain}

Pada saat sekarang SVM telah banyak diterakan pada bidang information retrieval. Sebagian besar penggunaan SVM pada information retrieval adalah pada pengklasifikasian dan pengkategorian dokumen, serta pada proses searching yang menerapkan relevancy feedback. Selain penggunaan pada dua hal tersebut, SVM juga digunakan untuk proses perengkingan pada document retrieval. Kemampuan SVM yang cepat walaupun untuk data berdimensi tinggi kadang-kadang menjadi solusi yang tepat untuk keperluan information retrival yang membutuhkan kecepatan.

Joachims (1998) mengenalkan SVM untuk text categorization. Di dalam tulisannya Joachims memberikan bukti secara teoritis dan secara eksperimen bahwa SVM sangat cocok untuk text categorization. Secara teoritis Joachims mengemukakan beberapa alasan mengapa SVM cocok digunakan untuk text categorization. Beberapa alasannya adalah sebagai berikut.

1. High dimensional input space: Pada text categorization akan didapati jumlah fitur yang sangat besar (lebih dari 10000), dan SVM cenderung tidak tergantung pada besarnya dimensi data.

2. Few irrelevant features: Karena sangat sedikit fitur-fitur yang tidak relevan, maka pemilihan fitur untuk tujuan mereduksi dimensi menjadi tidak efektif.

3. Document vectors are sparse: Vector-vector yang mewakili dokumen hanya memiliki sedikit bagian yang tidak bernilai 0. Kivinen, Warmuth, dan Auer (1995) memberikan bukti secara teoritis dan empiris, bahwa algoritma seperti SVM sangat cocok untuk menyelesaikan permasalahan seperti ini.

4. Most text categorization problems are linearly separable: Semua kategori dari data Ohsumed terpisah secara linear, begitu juga sebagian besar data Reuters. Ide dasar SVM adalah untuk medapatkan pemisah linear seperti itu.

Secara eksperimen, Joachims membandingakn SVM dengan beberapa algoritma lain yaitu, Bayes, Rocchio, R4.5, dan k-NN. Dari hasil eksperimen diketahui bahwa SVM menghasilkan performa yang baik, mengungguli algoritma-algoritma lainnya secara substansial dan signifikan.

Pada information retrieval, SVM juga digunakan pada proses relevance feedback. Pada information retrieval yang menggunakan relevancy feedback, feedback yang diberikan oleh user digunakan sebagai data training SVM, dimana selanjutnya classifier yang dihasilkan digunakan untuk menghasilkan result baru dengan tingkat relefansi lebih 
tinggi. Proses pemberian feedback ini bisa dilakukan secara iteratif. Drucker, Shahrary, dan Gibbon (2002) membandingkan SVM dengan beberapa algoritma lain untuk information retrieval menggunakan relevancy feedback.

Drucker, Shahrary, dan Gibbon (2002) membandingkan SVM dengan Rocchio, Ide, dan Ide dec-hi pada information retrieval dokumen teks menggunakan relevancy feedback. Dari kesimpulan yang diambil, Drucker, Shahrary, dan Gibbon kemudian memberikan 3 buah rekomendasi sebagai berikut.

1. Jika menggunakan TF-IDF weighting, dan dapat dipastikan bahwa pencarian awal dapat menghasilkan banyak dokumen yang relevan, maka SVM secara tipis lebih baik dari Ide dec-hi. Namun bagaimanapun, algoritma Ide dec-hi lebih simpel, lebih cepat, dan tidak perlu khawatir terhadap konvergensi algoritma SVM. Tidak pernah ada masalah dengan konvergensi, tapi hal itu bisa saja terjadi.

2. Jika lebih memilih untuk tidak menggunakan fitur TF-IDF, gunakan SVM dengan binary fiature weighting.

3. Gunakan SVM jika tidak bisa dipastikan seberapa berhasil pencarian awal yang akan dilakukan, karena jika pencarian awal jelek, maka algoritma-algoritma selain SVM akan memunyai performa yang buruk.

Pada information retrieval, SVM juga digunakan untuk proses perengkingan dokumen. Perengkingan dokumen berbasis SVM dikenalkan oleh Herbrich, Graepel, dan Obermayer (1999). Cao dkk.(2006) yang mengacu metode yang dikenalkan oleh Herbrich, Graepel, dan Obermayer sebagai Ranking SVM (RSVM) menggunakannya kembali untuk information retrieval dengan menambahkan dua pilihan optimasi, yaitu gradient descent dan quadratic programming, dan menamai metodenya Ranking SVM for IR (RSVM-IR).

Cao dkk. membandingkan RSVM-IR dengan BM25, dan language model for information retrieval (LMIR). Dari hasil percobaan yang dilakukan diambil kesimpulan bahwa RSVM-IR mengungguli Ranking SVM dan algoritma lainya secara signifikan.

Colas dan Brazdil (2006) membandingkan SVM dengan $k-N N$ dan Naive Bayes. Algoritma-algoritma dibandingkan dalam versi optimasi masing-masing. Hasil yang didapatkan menunjukkan bahwa semua algoritma mendapatkan performa yang sebanding di sebagian besar permasalahan. Satu hasil yang mengejutkan adalah SVM bukan merupakan pemenang sejati, meskipun cukup baik untuk performa keseluruhan. Jika preprocessing yang sesuai diterapkan pada $k-N N$, maka algoritma ini mendapatkan hasil 
yang sangat bagus secara terus menerus. Naive Bayes juga mendapatkan performa yang bagus.

\subsection{Langkah-langkah klasifikasi teks menggunakan SVM}

Proses klasifikasi teks dengan menggunakan SVM hampir sama dengan klasifikasi objek lain dengan menggunakan SVM. Perbedaannya terletak pada proses ekstraksi fitur. Pada information retrieval, proses ekstraksi fitur dikenal sebagai proses weighting. Secara garis besar langkah-langkah klasifikasi teks dengan SVM adalah indexing, weighting, training, dan testing.

\subsubsection{Indexing}

Indexing merupakan suatu preprocessing dalam klasifikasi teks. Jika dokumen yang akan diklasifikasi sudah mengalami indexing sebelumnya, maka proses klasifikasi cukup menggunakan index dokumen untuk ekstraksi fitur. Jika dokumen belum di index, maka pada proses klasifikasi diperlukan proses searching dan pengorganisasian terms yang prosesnya tidak sederhana. Proses indexing penting karena weighting menggunakan ada tidaknya atau jumlah suatu term pada dokumen.

\subsubsection{Weighting}

Proses weighting adalah kata lain dari ekstraksi fitur. Ada beberapa macam cara weighting, yaitu, binary weighting, term frequency (TF), inverse document frequency (IDF), dan perpaduan antara $T F$ dan $I D F$ disebut $T F-I D F$.

Binary weighting adalah pembentukan vektor fitur dengan melihat ada tidaknya suatu term di dokumen tersebut. $T F$ adalah pembentukan vektor fitur dari jumlah suatu term pada suatu dokumen. IDF adalah $T F$ dikalikan dengan $\log \left(N / n_{i}\right)$ dimana $N$ adalah jumlah keseluruhan dokumen, dan $n_{i}$ adalah jumlah dokumen yang mengandung term tersebut. $T F-I D F$ adalah kombinasi $T F$ dan $I D F$ dimana $T F$ dikalikan oleh $I D F$.

Pertama-tama ruang vektor fitur dibentuk dengan menghitung jumlah jenis kata yang terdapat di seluruh dokumen. Jika pada keseluruhan dokumen terdapat 1000 yang berbeda, maka vektor fitur akan berdimensi 1000, dimana setiap bagian vektor mewakili satu kata. Dimensi vektor dapat direduksi dengan cara mem-prunning kata-kata yang tidak signifikan.

Setelah ruang vektor terbentuk, selanjutnya vektor-vektor yang mewakili suatu dokumen dibentuk dengan menggunakan salah satu metode weighting. Misalkan dari koleksi dokumen yang terdiri dari 500 dokumen ditemukan 1000 jenis kata yang berbeda, 
jika tidak dilakukan prunning, maka akan didapatkan ruang vector berdimensi 1000 . Misalkan dimensi pertama mewakili kata "bola", dan dimensi ke-2 mewakili kata "buku", maka jika pada dokumen pertama terdapat kata "bola" dan tidak terdapat kata "buku", jika menggunakan binary weighting, maka vector yang mewakili dokumen pertama dimensi pertamanya akan bernilai 1 dan dimensi ke-2 nya bernilai 0 . Jika dimensi pertama disebut $\mathrm{x}_{1}$ dan dimensi ke-2 disebut $\mathrm{x}_{2}$ maka $\mathrm{x}_{1}=1$, dan $\mathrm{x}_{2}=0$, dan seterusnya. Jika pada dokumen pertama terdapat 25 buah kata "bola" dan 5 buah kata"buku", jika menggunakan $T F$ maka vektor fitur untuk dokumen pertama $\mathrm{x}_{1}=25$, dan $\mathrm{x}_{2}=5$. IDF jarang dipergunakan karena prosesnya yang lebih komplek. Pada $I D F$ vektor fitur baru dapat dibentuk setelah melakukan pernghitungan pada seluruh dokumen.

\subsubsection{Training}

Setelah vektor-vektor fitur terbentuk, lengkap dengan labelnya masing-masing, maka vector-vector tersebut telah siap dimasukkan ke SVM untuk dijadikan data training. Yang perlu dijadikan perhatian pada proses training adalah permasalahan tunning terhadap parameter-parameter SVM. Penentuan parameter yang tepat akan menghasilkan classifier yang lebih baik. Namun permasalahannya adalah, sampai saat ini belum ada teori yang bisa menjadi dasar bagaimana cara untuk menentukan parameter-parameter SVM secara tepat. Selama ini cara yang dilakukan adalah metode coba-coba melalui proses iterasi. Selain itu untuk menentukan jenis kernel yang dipakaipun seharusnya terlebih dahulu harus diketahui sifat-sifat data, namun pada kenyataannya hal ini jarang terjadi. Sehingga untuk data yang tidak diketahui sifatnya, para peneliti lebih memilih menggunakan RBF kernel.

Hasil keluaran SVM dari proses training adalah nilai alpha untuk setiap vektor dan sebuah nilai $b$. Untuk vektor yang bukan merupakan support vectors, nilai alpha-nya akan bernilai 0. Classifier akan dibentuk oleh nilai-nilai alpha dan nilai $b$.

\subsubsection{Testing}

Pada saat testing diperlukan nilai-nilai alpha dan nilai $b$ yang didapatkan pada saat training untuk melakukan proses klasifikasi. Vektor-vektor fitur yang dijadikan data testing dimasukkan ke SVM tanpa disertai labelnya beserta nilai-nilai alpha dan $b$. Keluaran hasil testing berupa label class hasil klasifikasi. Untuk mengecek tingkat akurasi classifier, label keluaran ini kemudian dibandingkan dengan label aslinya. 


\subsubsection{Masalah Multiclass}

Sebagian besar permasalahan klasifikasi yang dijumpai pada klasifikasi teks bersifat binary classification, misalnya pada proses filltering, yang dibutuhkan adalah jawaban ya atau tidak, pada relevancy feedback yang diperlukan adalah jawaban relevan atau tidak. Namun dalam beberapa kasus, permasalahan multiclass bisa muncul. Melihat sifat dasar SVM yang merupakan sebuah binary classifier, maka diperlukan suatu sekenario untuk menggunakan SVM sebagai multiclass classifier.

Ada dua sekenario yang sering digunakan, yaitu sekenario one against one, dan one against all. Pada sekenario one against one dibuat sejumlah classifier yang memisahkan satu class dengan satu class lain. Setiap pasangan class diadu satu sama lain, class yang paling menang dijadikan sebagai class label akhir. Pada sekenario one against all, dibuat sejumlah classifier yang memisahkan satu class dengan semua class lainnya. Di saat data masuk ke suatu class dimana menghasilkan jarak yang paling jauh dari hyperplane, maka kelas tersebut dijadikan class label data tersebut. Untuk jumlah kelas yang banyak, sekenario one against one sulit untuk dilakukan, karena akan diperlukan banyak sekali classifier.

\subsubsection{Masalah Perengkingan}

Masalah perengkingan biasanya timbul pada saat pengembalian suatu hasil query. Kadang kala, tidak semua hasil query yang bisa didapatkan oleh mesin disuguhkan kepada user, dan mungkin hanya sebagian kecilnya saja. Dari itu diusahakan supaya hasil yang ditampilkan kepada user adalah hasil yang paling baik. Untuk itu diperlukan suatu proses perengkingan.

Proses perengkingan pada pengembalian hasil query mirip dengan proses sekenario one against all pada kasus klasifikasi multiclass. Bedanya adalah pada proses perengkingan ini hanya ada satu classifier. Nilai rengking ditentukan dari seberapa jauh letak vektor fitur dari hyperplane. Semakin jauh letak vektor fitur dari hyperplane, semakin jelas bahwa data tersebut masuk ke class tersebut, maka semakin baik rengking nya.

\section{PENUTUP}

SVM dapat diterapkan pada berbagai bagian dalam information retrieval, seperti pengklasifikasian dan pengkategorian dokument atau teks, proses relefancy feedback, dan perengkingan dokumen. Kemampuan SVM yang tidak terpengaruh dimensi data sangat cocok untuk menyelesaikan masalah-masalah yang berkaitan dengan dimensi besar pada 
information retrieval yang tidak bisa ditanggulangi oleh algoritma-algoritma lain. Dari hasil beberapa percobaan yang dilakukan oleh beberapa peneliti, dalam beberapa kasus, SVM sangat singnifikan mengungguli algoritma lain. Dalam percobaan yang lain ditunjukkan bahwa SVM mempunyai performa berimbang dengan beberapa algoritma lain dalam beberapa kasus.

\section{DAFTAR PUSTAKA}

Cao, Y., dkk. 2006. Adapting Ranking SVM to document retrieval. SIGIR '06 Proceedings of the 29th annual international ACM SIGIR conference on Research and development in information retrieval. Page 186-193.

Colas, F., Brazdil, P. 2006. Comparison of SVM and some older classification algorithms in text classification tasks. Artificial Intelligence in Theory and Practice. Page 169178. Springer US.

Drucker, H., Shahrary, B., Gibbon, D. C. 2002. Support Vector Machines: Relevance feedback and information retrieval. Information Processing and Management 38, 305-323. Pergamon.

Fletcher, T. 2009. Support Vector Machine explained. UCL. www.cs.ucl.ac.uk/staff/T. Fletcher/.

Herbrich, R., Graepel, T., Obermayer, K. 1999. Large margin rank boundaries for ordinal regression. Advances in neural information processing systems. Page 115 132. MIT.

Joachims, T. 1998. Text categorization with Support Vector Machines: Learning with many relevant features. Machine Learning: ECML-98, Lecture Notes in Computer Science Volume 1398, 1998, pp 137-142. Springer Berlin Heidelberg.

Kivinen, J., Warmuth, M. K., Auer, P. 1995. The Perceptron algorithm versus Winnow: linear versus logarithmic mistake bounds when few input variables are relevant. Artificial Intelligence 97 (1997) 325-343. Elsevier. 